\title{
La propuesta arqueológica de Enrique Dussel en el contexto discursivo de la filosofía de la religión latinoamericana
}

\section{Enrique Dussel's Archeological Proposal in the Discursive Context of Latin American Philosophy of Religion}

\author{
Juan Matías Zielinski \\ CONICET / Universidad de Buenos Aires, Argentina \\ jmzielinski@gmail.com \\ Recibido: 13/05/2016 • Aceptado: 02/02/2017
}

\section{Resumen}

Se presenta un estudio filosófico dedicado al análisis del contexto discursivo en el que se inscribió e inscribe la propuesta arqueológica de Enrique Dussel: la filosofía de la religión expuesta en su obra filosófica temprana. Esta formulación se enmarca en el desarrollo histórico y conceptual de la disciplina en nuestro continente y, de modo más directo, en marco categorial de la filosofía de la religión como se presenta en la filosofía de la liberación. Con este objetivo principal, el trabajo se estructura del siguiente modo: en el primer apartado se presenta un análisis secuenciado históricamente de los principales «nudos filosóficos» de esta doctrina, puestos de relieve en el devenir histórico de la disciplina en nuestra región y, posteriormente, se realiza un bosquejo general de las líneas de investigación predominantes en la actualidad. En el segundo apartado, se analizan las notas esenciales de la formulación arqueológica de Enrique Dussel, tomando como referencia principal los

\section{Abstract}

This philosophical article analyzes the discursive context of Enrique Dussel's arqueological thought: the Philosophy of Religion that he presented in his early philosophical work. This formulation is framed in the historical and conceptual development of the discipline in Latin America and, chiefly, in the theoretical framework of Liberation's Philosophy of Religion. To achieve the main objective, it presents, in the first section, a historically sequenced analysis of the philosophical issues highlighted in the historical development of this discipline in our continent and, subsequently, a global mapping of the most important current lines of research; In the second section, it shows an analysis of the essential notes of Enrique Dussel's archaeological proposal, taking as reference the analyzes presented by other researchers on his proposal. In the third section, it shows the discursive belonging of Dusselian Archeology to the theoretical framework of Liberation's Philosophy of 
análisis que otros destacados investigadores han realizado sobre su propuesta. En el tercer apartado, se muestra la pertenencia discursiva de la arqueológica dusseliana en el marco categorial de la filosofía de la religión de la liberación, demostrando que dicha formulación debe ser comprendida en un contexto discursivo específico. Finalmente, se presentan algunas reflexiones conclusivas.
Religion, demonstrating that this formulation must be understood in a specific discursive context. Finally, it exposes conclusive reflections.

Keywords: Archeology, discursive context, Enrique Dussel, Philosophy of Religion, Liberation's Analectical Philosophy.

Palabras clave: arqueológica,

contexto discursivo, Enrique Dussel,

filosofía de la religión, filosofía

analéctica de la liberación. 


\section{Introducción}

Considero de gran relevancia teórica y práctica la elaboración de una filosofía de la religión latinoamericana que asuma el análisis crítico de las problemáticas más urgentes de nuestra propia situacionalidad histórica. Entiendo que tales «emergentes contextuales» de carácter configurador, en tanto que condiciones condicionantes no determinantes, permiten elaborar una amplia gama de categorías filosóficas capaces de contribuir a la comprensión y a la transformación de las problemáticas propias de nuestra región, en lo que se refiere de manera especial a aquellas que requieren poner de manifiesto la mutua implicación entre los factores religiosos y los principios ético-políticos.

Asimismo, entiendo que la filosofía, como ejercicio práxico comprometido, debe en primer lugar tomar a su cargo, por «concernimiento» ético-epistémico, su propia situacionalidad históricocontextual para, desde ahí, y como lugar privilegiado de enunciación, elaborar un discurso crítico que favorezca procesos efectivos de transformación de las realidades históricas periféricas (latinoamericanas y mundiales). En ello, la filosofía de la religión ocupa un lugar preferencial. Sin embargo, advierto, como lo hacen la mayoría de los investigadores expertos en el área, que el campo de la filosofía de la religión latinoamericana ha producido solo recientemente algunos desarrollos significativos. Es decir, si bien es notorio que en nuestros países ha habido y hay muy meritorios filósofos de la religión, esto no equivale a decir que haya existido un desarrollo prolífico de la disciplina, si por ello se entiende el desarrollo de una discursividad filosófica abocada a la relación entre el ser humano y lo Santo que toma a su cargo, críticamente, la propia situacionalidad contextual y los problemas que de ella emergen. Por ello, puedo afirmar que el campo de la filosofía de la religión latinoamericana exhibe un escaso desarrollo sistemático precedente. 
Sin embargo, esta disciplina se presenta a las nuevas generaciones de pensadores y pensadoras como un suelo fértil para comenzar a producir conocimientos inéditos y culturalmente significativos que logren relacionar, con pertinencia histórico-política, las cuestiones atinentes a la religión desde categorías filosóficas universalmente situadas. En la actualidad, se evidencia un creciente interés en la investigación filosófica por la cuestión religiosa y, sobre todo, por la configuración situacional de sus planteamientos (particularmente, en lo atinente a los aspectos ético-políticos). Así, este estudio tiene la intención de contribuir al desarrollo de este complejo campo temático desde una perspectiva contemporánea que, a la vez, retome los mejores hallazgos de la tradición filosófica latinoamericana.

Considero que la atención emergente que actualmente recibe este campo de estudio es palpable en la presente situación sociopolítica de América Latina. Advierto una significativa actualidad de la relación entre política y religión, sobre todo en la discursividad trans-moderna de los movimientos sociales y políticos de nuestra región. Por tal motivo, resulta relevante explicitar un discurso filosófico que exponga de manera específica la relación co-implicante entre los factores ético-políticos y los religiosos, ya que tal mixtura es un elemento constituyente de las construcciones semánticas, simbólicas y discursivas de nuestra cultura en el presente histórico. En definitiva, y como mencioné previamente, estimo que es una tarea indelegable de la filosofía latinoamericana actual llevar adelante un estudio crítico de la relación entre la racionalidad simbólico-mítica y la praxis económico-política.

Se presenta en este artículo un breve estudio filosófico dedicado al análisis del contexto discursivo en el que se inscribió e inscribe la formulación arqueológica de Enrique Dussel: ${ }^{1}$ la filosofía de la religión expuesta en su obra filosófica temprana. Ésta se enmarca en el desarrollo histórico y conceptual de la disciplina en nuestro

1 Metodológicamente, este trabajo no intenta ser un estudio que historie ideas -aunque recurra a algunas periodizaciones epocales- sino, más bien, una reconstrucción conceptual de los grandes «nudos filosóficos» que configuraron y configuran un «contexto discursivo» condicionante. En este caso, el de la filosofía de la religión en América Latina y, más particularmente, el de la Filosofía «analéctica» de la liberación. 
continente y, de modo más directo, en el entramado discursivo propio del marco categorial de la filosofía «analéctica» de la liberación. ${ }^{2}$ Persiguiendo el mencionado objetivo principal, este trabajo se estructura del siguiente modo: en el primer apartado, se presenta un análisis secuenciado históricamente de los principales «nudos filosóficos» puestos de relieve en el devenir histórico de la disciplina en nuestra región y, posteriormente, se realiza un bosquejo general de las líneas de investigación predominantes en la actualidad. En el segundo apartado se presentan, indicativamente, las notas esenciales de la formulación arqueológica de Enrique Dussel, tomando como referencia principal los análisis que otros destacados investigadores han realizado sobre su propuesta. En el tercer apartado se muestra la pertenencia discursiva de la arqueológica dusseliana en el marco categorial de la filosofía de la religión de la liberación, demostrando que tal formulación debe ser comprendida en un contexto discursivo específico que la enmarca, limita y orienta. Finalmente, se presentan algunas reflexiones conclusivas.

\section{La filosofía de la religión en América Latina:Antecedentes y actualidad}

Para ganar en precisión y sistematicidad durante esta exposición sobre la situación actual de la filosofía de la religión en Latinoamérica, estructuraré este apartado con base en dos descripciones que considero fundamentales: primero, propondré una breve reflexión

2 Desde su fundación en Argentina, el movimiento intelectual de la Filosofía de la liberación ha sido sumamente heterogéneo. Por ello, y conociendo suficientemente las profundas diferencias teórico-prácticas entre las diversas corrientes que lo conforman, tomaré como principal interlocutor a Juan Carlos Scannone, quien se ubica en una línea de investigación cercana a la de Enrique Dussel: la «corriente analéctica». Tratar las divergencias entre ambos autores excede por mucho el alcance de este artículo, aunque vale la pena indicar que existen y de manera muy acentuada, aunque en el marco de la generalidad que los une -antecedentes de formación, influencias teóricas, puntos de partida de la reflexión filosófica y configuración cultural-. Cada uno representa un proyecto filosófico con identidad propia, distintos $y$, en algunos puntos, hasta antagónicos entre sí. Sin embargo, en lo que se refiere al tema de esta breve contribución, Scannone debe ser el interlocutor principal, dado que, en la actualidad, es el filósofo de la religión latinoamericana más original y consistente. 
histórica sobre el derrotero de la filosofía de la religión «en» Latinoamérica y «latinoamericana» a partir del comienzo del siglo XXI y hasta su final y un bosquejo general de la situación actual de la filosofía de la religión en Latinoamérica y en latinoamericana, a partir del comienzo del siglo XXI..

En principio, presentaré las etapas históricas que constituyen, más significativamente, los antecedentes del tratamiento filosófico de la religión en América Latina, refiriéndome, específicamente, a las contribuciones del siglo XX. Para ello, tendré en cuenta, especialmente, la esquematización de las etapas, las corrientes y los principales autores que conforman el corpus teórico más relevante de esta disciplina. En este sentido, y siguiendo a Scannone, cabe distinguir los siguientes períodos o etapas históricas constituyentes, a saber:

El primer período, de los «fundadores de la filosofía latinoamericana», se caracteriza por un «espiritualismo antipositivista» ya que, aunque sus representantes "no se dedicaron específicamente a la filosofía de la religión (...), le proporcionaron sólidas bases espiritualistas" (Scannone, 2013: 1). Durante este período, los autores más relevantes y sus ideas centrales fueron: José Vasconcelos (1882-1959), quien expuso un «monismo estético» como modo de elevación del ser humano hacia lo divino a partir de un "a priori estético” (Vasconcelos, 1952-1959); Raimundo de Farías Brito (18621917), a partir de una "importante inquietud religiosa" (Scannone, 2011: 582) sostuvo una posición filosófica cercana al panteísmo; José Enrique Rodó (1871-1917), por su parte, consideró la cultura clásica y el «humanismo cristiano» como fuentes de su «arielismo iberoamericanista» (Rodó, 2005); Carlos Vaz Ferreira (1872-1959) defendió la enseñanza de «aspiración religiosa» de la filosofía, sin otorgarle, no obstante, una dirección confesional determinada; Alberto Rougès (1880-1945, se caracterizó por su meditación sobre el ser y sobre la eternidad a partir de un diálogo crítico tanto con San Agustín como con Henri Bergson (Rougès, 1943); Antonio Caso (1883-1946), filósofo cristiano mexicano, presentó una comprensión de la existencia a partir del desinterés y la caridad; Víctor A. Belaúnde (1883-1928), a su vez, se dirigió "hacia la fe por la filosofía" (con una importante influencia agustiniana); Jackson de Figueiredo 
(1891-1928); y, finalmente, Coriolano Alberini (1886-1960), quien reconoció el "impulso vital humano hacia lo incondicionado" (Scannone, 2011: 582); entre otros.

Scannone define la segunda etapa como la de los «forjadores» porque considera a estos filósofos los protagonistas de la normalización de los estudios filosóficos superiores en América Latina (impulsada por Francisco Romero, hacia 1930). El proceso de normalización se caracterizó por la formulación de una «metafísica religiosa» y de una «filosofía de la religión explícita». A continuación, me referiré a los exponentes más significativos de esta "filosofía de la religión «no onto-teo-lógica» a partir de la metafísica del ser" (Scannone, 2013: 3). En primer lugar, Miguel Ángel Virasoro (1900-1967) presentó una «fenomenología dialéctica» y una «filosofía de la existencia» basadas en la «intuición metafísica» del ser y serse (Virasoro, 1965), planteando tres dimensiones de la trascendencia: la «abisal», la «colateral» y la «cenital». En todo caso, y según los fines de este artículo, es importante subrayar que el autor indicó, a través de la «figura» de la trascendencia, un «más allá» no conceptualizable que excede la razón y la conciencia humanas. De este modo, superó la onto-teo-logía al postular que la Divinidad trasciende el ser. Así, la «intuición metafísica» es la intuición de un «más allá» inefable que rebasa la conciencia con su «presencia ausente» (Virasoro, 1965: 150). Un segundo exponente relevante de la «metafísica religiosa» fue Ángel Vassallo (1902-1972), quien pensó una «trascendencia en la inmanencia» a partir de la «experiencia metafísica» como presencia del infinito «en» lo finito, postulando una comprensión «transobjetual» de la trascendencia; es decir: no onto-teo-lógica (Vassallo, 1950).

Otra corriente, también representativa de esta etapa, es la que Scannone caracteriza como una filosofía de la religión explícita (Scannone, 2011: 583). Vicente Fatone (1903-1962) desarrolló, en América Latina, uno de los primeros planteos explícitos de filosofía de la religión (García Bazán, 1980). Según este autor, la religión se funda en un «sentimiento de absoluta independencia» de Dios respecto de todo lo otro. Por eso es que a partir del conocimiento místico, como conocimiento trans-objetivo de presencia, comunicación 
y silencio, se puede «decir todo» renunciando a «decir nada» $(\mathrm{Fa}-$ tone, 1955). Sobre esta corriente de pensamiento, explica Scannone: "en Virasoro y Vassallo, su comprensión de Dios ha superado toda ontoteología (...) en el primero, no sólo es transóntica, sino también transontológica (como lo va a ser luego en Lévinas, Dussel y Marion)" (Scannone, 2011: 583). Otros dos referentes importantes de esta generación son Luis Farré (1902-1997) (Farré, 1969) e Ismael Quiles (1906-1993). Quiles, con fuerte influencia de San Agustín, propuso, a partir de su «filosofía insistencial» (Quiles, 1958; 1980) una concepción de la persona humana que "insiste en sí, como «interinsistencia» (en relación con los otros) y como «insistencia» enraizada en Dios («sistencia absoluta») ${ }^{3}$. Por su parte, Víctor Massuh (19242008) se abocó al análisis del rito (Massuh, 1965) y, como estudioso del nihilismo nietzcheano contemporáneo, propuso superar las «agonías de la razón» a partir de una «experiencia extrema» de recogimiento en libertad creadora (Massuh, 1975) (opuesta a todo tipo de fanatismo ideológico o religioso). ${ }^{4}$ Ambas líneas de pensamiento, tanto la metafísica religiosa como la filosofía de la religión explícita, convergieron desde "un punto de vista superior más abarcativo" (Scannone, 2013: 6) en Henrique de Lima Vaz (1921-2002) (Vaz, $1968 ; 1986 ; 1988 ; 1991 ; 1992 ; 2000)$.

Otro movimiento de auténtica notoriedad en el siglo XX latinoamericano fue el denominado «neo-escolástico»-cuya influencia fue significativa hasta el Concilio Vaticano II-. Contó, entre sus mayores representantes, con figuras como Leonel Franca (1893-1948), Octavio N. Derisi (1907-2002), Agustín Basave Fernández del Valle (1923-2006) y Alberto Caturelli (1927-2016). Estos filósofos abordaron la cuestión religiosa a través de una «teología filosófica» siguiendo la tradición agustiniana y, fundamentalmente, la tomista (Scannone,

3 Es importante destacar, a la luz del desarrollo posterior de la filosofía latinoamericana, que "tanto Fatone como Quiles plantean una filosofía de la religión intercultural avant la lettre" (Scannone, 2011: 583).

4 Scannone sostiene que esa línea de investigación caracterizada por ser una filosofía de la religión «espiritual» es hoy continuada por Francisco García Bazán, sobre todo en referencia a sus estudios sobre el neo-platonismo y el gnosticismo, así como en los referidos a lo sagrado (García Bazán, 1999). 
2011: 584). Mella considera que este movimiento, más que una «filosofía cristiana», representa un conjunto de filósofos cristianos que reflexionaron filosóficamente a partir de su cosmovisión religiosa, destacándose entre ellos: Alberto Caturelli, Agustín Basave Fernández del Valle y José Rubén Sanabria (Mella, 2014: 193-194). Según Mella, la filosofía neo-escolástica tuvo, en América Latina, tres etapas (Mella, 2014: p193-194): la primera, de «formación y organización» del movimiento neo-escolástico (1911-1940), se caracterizó por la intención de los grupos neo-escolásticos de «ganar espacio público» para la fe católica en un contexto donde primaba el pensamiento positivista y el laicismo krausista; la segunda, de «expansión y diálogo» (1941-1960) se caracterizó por un mayor estudio de las fuentes de la escolástica, por la profundización del diálogo con la filosofía contemporánea y por una importante proyección de su filosofía en el medio universitario. ${ }^{6}$ En la tercera etapa, de «disolución y concentración» (1961-1986), se considera de fundamental relevancia el aporte del argentino Octavio Nicolás Derisi.

Aproximadamente desde 1970, la filosofía de la religión en Latinoamérica comienza a producirse a partir del marco categorial de la «filosofía de la liberación», ${ }^{7}$ estableciéndose lo que denomino una filosofía de la religión propiamente latinoamericana. Este momento

5 Según Mella, en esta etapa los autores neo-escolásticos se propusieron recuperar las «raíces culturales cristianas de América Latina» pero con una intención marcadamente apologética (esta «actitud» es la que Mella considera puede ser una de las causas principales de la decadencia posterior en la que cayó la neo-escolástica en América Latina) (Mella, 2014: 194).

6 En este sentido, el autor señala que Quiles, a quien incorpora dentro de esta corriente, fue un verdadero ejemplo de diálogo con otros modos de pensar.

7 Algunas de las producciones en las que se puede encontrar un análisis general del movimiento de la filosofía de la liberación son: Historia del pensamiento filosófico latinoamericano. Una búsqueda incesante de la identidad (Beorlegui, 2010: 661-695); filosofía de la liberación latinoamericana (Cerutti-Guldberg, 2006); "Filosofía de la liberación" en el Diccionario de filosofía latinoamericana (García Clarck, 2000 en Cerutti-Guldberg, 2000: 169-170); "Filosofía/Teología de la liberación" en Pensamiento Crítico Latinoamericano. Conceptos Fundamentales (Scannone, 2005d en Salas Astraín, 2005: 429-441); “La filosofía de la liberación: historia, características, vigencia actual" (Scannone, 2009a: 5973); "La filosofía de la liberación” (Solís Bello Ortiz et. al., 2011en Dussel et. al., 2011: 399417); "Las filosofías de la liberación" (Samour, 2014 en Beorlegui y Fornet-Betancourt, 2014: 213-245). 
también podría caracterizarse como el de la filosofía de la religión en la filosofía de la liberación. ${ }^{8}$ Sobre todo en la «corriente analéctica» de la filosofía de la liberación (me refiero principalmente a Enrique Dussel y a Juan Carlos Scannone) se hace explícita la formulación sistemática de una filosofía de la religión «latinoamericana»:

No es de extrañar que en la filosofía de la liberación haya aportaciones importantes para una Filosofía de la religión, pues aquélla replantea de manera nueva todos los grandes temas del filosofar (incluidos los de Dios y la religión) desde su punto de partida y su lugar hermenéutico propios, a saber, respectivamente, la interpelación ético-histórica de los pobres latinoamericanos (aún al filósofo como tal) y la opción (también teórica) por su liberación integral, que les responde responsablemente (Scannone, 2011: 586).

La cuestión de la filosofía de la religión «en» la filosofía de la liberación pone de manifiesto, como muchos otros elementos, los diversos puntos de vista que convergieron en el heterogéneo movimiento filosófico. Con respecto a sus variantes internas, podría hablarse de una corriente caracterizada por un énfasis de tipo «ético-cultural» y de otra corriente que, en mayor o en menor grado, estaría orientada por el marxismo. ${ }^{9}$ Esta diferenciación se configura,

8 Según Mella, la Filosofía de la liberación formaría parte de la "filosofía cristiana no escolástica en América Latina" (Mella, 2014: 194). En esa clasificación, el autor sigue las consideraciones vertidas en "Filosofía cristiana no escolástica en Latinoamérica" (Domínguez Miranda, 1997 en Coreth, E. et. al., 1997: 624-687). Esta apreciación es correcta solo si se toma como referencia principal del movimiento filosófico a la corriente analéctica.

9 La clasificación que toma como criterio de referencia el instrumental categorial o la mediación analítica utilizada fue realizada por Raúl Fornet-Betancourt (Fornet-Betancourt, 1988: 65-85) y retomada por J.C. Scannone (Scannone, 2009a: 62). Por otro lado, contamos con la tan clásica como problemática clasificación realizada por Horacio Cerutti-Guldberg. El autor argentino-mexicano toma como criterio la relación con el "populismo», que demarcaría las corrientes internas entre: populismo concreto; populismo abstracto; crítica historicista y, finalmente, problematizadora (Cerutti-Guldberg, 2006: 302-472). Posteriormente, entre la corriente ontologicista (Kusch, entre otros), analéctica (Dussel y Scannone, entre otros), historicista (Roig, entre otros) y problema- 
básicamente, por el instrumental categorial que cada una emplea: mientras que la «ético-cultural» utiliza una mediación de tipo hermenéutica (de los símbolos contenidos en la «sabiduría popular»), la corriente orientada por el marxismo utiliza una mediación analítica de tipo económico-política. Dentro de la corriente «ético-cultural» se destacan los desarrollos teóricos de Rodolfo Kusch (1922-1979), de Carlos Cullen (1943-) y de Juan Carlos Scannone (1931-). ${ }^{10}$ En

tizadora (Cerutti-Guldberg, entre otros) (Cerutti-Guldberg, 1989: 65-83). Estas clasificaciones son recuperadas y analizadas en Historia del pensamiento filosófico latinoamericano. Una búsqueda incesante de la identidad (Beorlegui, 2010: 695-791); en La liberación indígena contemporánea en Bolivia. Crítica filosófica a una política-estética racionalizada (Cruz, 2009: 33-74) y en el artículo "Las filosofías de la liberación" de la Guía Comares de filosofía latinoamericana (Samour, 2014 en Beorlegui y Fornet-Betancourt, 2014: 213-245). Por mi parte, considero que la propuesta por R. Fornet-Betancourt es la más adecuada. Sin embargo, valoro de la clasificación que presenta $\mathrm{H}$. Cerutti-Guldberg el haber indicado de manera precisa, aunque críticamente, que la nota distintiva de la producción de Dussel y de Scannone radica en la utilización del método analéctico.

10 Cada uno de estos autores amerita la realización de un trabajo específico dedicado a sus obras. Sin embargo, por los límites inherentes a esta presentación, sólo indicaré sus obras más relevantes en lo que respecta a la formulación de una filosofía de la religión latinoamericana. En la obra de Kusch, se destaca la categoría de «estar», que expresa el arraigo originario del hombre en la tierra a partir de un potencial simbólico y de religación religiosa. Postula un pensamiento trans-objetivo, trans-categorial, sapiencial y seminal movido por la lógica de la negación que opera, sobre todo, con símbolos y ritos (más que por la univocidad del concepto) (Kusch, 1962; 1973; 1975; 1977). Según Solari, en el pensamiento de Kusch la "metafísica es inseparable de la religiosidad y viceversa" (Solari, 2005: 135). En el caso de Cullen, el autor ubica como punto de partida de su fenomenología (fenomenosofía) la experiencia sapiencial de los pueblos en tanto que "nosotros estamos en la Tierra» concebida como "ético-religiosa", tanto por su "estar" en la "tierra" -religación con lo sagrado- como porque el sujeto es un nosotros -relación ética-. A partir de ello es que se descubre la presencia del «Infinito vertical» (Cullen, 1978; 1986; 1986b; 1987). En el caso de Scannone se trata, por mucho, del filósofo de la religión más importante de la filosofía de la liberación, ya que ha formulado explícitamente una filosofía de la religión latinoamericana de desarrollo sistemático. Su planteamiento se asienta sobre la superación tanto de la metafísica de la sustancia como del sujeto tomando como punto de partida de su reflexión no sólo la interpelación ética y la enseñanza de los pobres (Lévinas) sino, más allá de éste, la experiencia práctica e histórica de liberación. Su propuesta parte de la «sabiduría popular» de los pobres, llevando a concepto (aunque sin violentar su plurisemia, es decir, de modo analógico) sus símbolos, ritos, fiestas y la creatividad de su praxis histórica (social, cultural, política y religiosa). Asume tanto la fenomenología levinasiana (vía corta) como la hermenéutica ricoeuriana (vía larga) mediando la «Fenomenología del rostro» a través de la hermenéutica simbólica, o sea, situándola histórica y geoculturalmente. Al igual que Dussel, emplea el método analéctico (ana-dia-léctico para Dussel), que asume no 
cuanto a la corriente “orientada por el marxismo", su máximo exponente es Enrique Dussel (1934-) ${ }^{11}$ junto a Franz J. Hinkelammert (1931-). Otro autor indispensable dentro de la filosofía de la religión en la filosofía de la liberación, y por fuera de las dos corrientes antes mencionadas dada su fuerte impronta zubiriana, es Ignacio Ellacuría. ${ }^{12}$

En cuanto a la situación actual de las investigaciones referidas al tema del presente artículo, se puede constatar que en las últimas dos décadas del siglo XX se comenzaron a formular algunas propuestas novedosas, como se evidencia, por ejemplo, en Filosofía de la religión (Marquínez Argote, 1981), Al encuentro de Dios. Filosofía de la religión (Vélez Correa, 1991) o en el artículo "Filosofia della religione" (Brito, 1992: 17-40), entre otros. Como síntesis del desarrollo conceptual

sólo el momento crítico-negativo de negación de la negación (conflicto histórico), sino también, y principalmente, el de la afirmación meta-física del Otro (positividad originaria). Fruto de ello, propone una «filosofía inculturada», comprendiendo la sabiduría popular como «mediación» entre la religión y el lenguaje (religioso y analógico) (Scannone, 1976; 1989; 1990; 1993; 2005a; 2005b; 2005C; 2005d; 2009a; 2009b; 2010a; 2010b; 2011; 2012; 2013; 2015).

11 De todos modos, es menester destacar que la formulación de la «Arqueológica» (filosofía de la religión o mítica) fue escrita durante su obra filosófica temprana, redactada entre 1974 y 1975 y publicada, posteriormente, en 1980; es decir, en su «etapa» pre-marxiana, antes de su exilio en México. Sin embargo, y si se atiende al desarrollo completo de la obra de Enrique Dussel, la categorización es pertinente. Sobre todo, si se adhiere a su comprensión del fenómeno religioso la publicación Religión (Dussel, 1977b), en donde ya se aprecia con claridad la asunción de su incipiente estudio de Marx.

12 La filosofía de la religión de Ellacuría, de inspiración zubiriana, tiene por objeto como su filosofía en general- la «realidad histórica», en la cual Dios no queda excluido pero se lo debe comprender a partir de su alteridad; es decir, no como a las cosas, respectivas entre sí en una totalidad. En ella, la religación se presenta como la estructura o actitud radical de la persona humana en cuanto ésta está religada al «poder de lo real» que es ya «presencia ausente» de la realidad absoluta de Dios. Será sólo al nivel del lógos donde la religación puede o no hacerse religión. En definitiva, su filosofía de la realidad histórica intenta promover y sistematizar la praxis histórica de liberación, ya que, como en Kant, Dios sólo puede ser encontrado a través la razón práctica; es decir: en la praxis liberadora en favor de los «crucificados de la historia» y de las «mayorías populares» (Ellacuría, 1981; 1985; 1990; 2000; 2001). Sobre ello, indica Scannone: "nuestro autor, sin desarrollar una filosofía de la religión, la ubica certeramente en una metafísica de la realidad histórica, a través de la experiencia zubiriana de la religación personal, y -en forma más original- a través de la apertura trascendental de la realidad histórica considerada como praxis" (Scannone, 2011: 589). 
de la filosofía de la religión en Latinoamérica durante el siglo XX, explica Scannone:

En sus exponentes más conspicuos, la filosofía de la religión latinoamericana del siglo XX no ha caído en las objetivaciones del pensamiento representativo al pensar a Dios o lo sagrado, sino que -mediante distintos caminos, como son la poesía, el símbolo, la negación y la analogía- trasciende «más allá o más acá» de lo objetual y lo óntico, y aun de lo ontológico. Para ello encuentra, con relativa frecuencia, fuentes inspiradoras tanto en la cultura cristiana ambiente, como en religiones orientales -por ejemplo, de la India-, sin omitir las aborígenes y la religiosidad popular latinoamericana, de modo que en no pocas ocasiones procede en forma intercultural (Scannone, 2013: 21).

Sin embargo, es cierto aquello que indica Vicente Durán Casas cuando afirma: "la vastísima reflexión teológica y pastoral, que ha enriquecido y fecundado las religiosidades latinoamericanas en los últimos años, contrasta con la poca acogida que ha tenido la reflexión filosófica sobre el fenómeno religioso en América Latina" (Durán Casas, 2003: 11). En la misma dirección, asevera más drásticamente Solari: "la filosofía de la religión en la América de habla hispana no ha pasado de intentos fragmentarios, por lo general carentes de sistemacidad, precisión y exhaustividad" (Solari, 2005: 127). ${ }^{13}$

De todos modos, también se puede constatar que en la primera década del siglo XXI hubo un notorio despertar de la disciplina en América Latina. Se evidencia con claridad que, en los primeros años del siglo XXI, hay un creciente interés tanto por el estudio del pensamiento latinoamericano, en general, como por el de la filosofía de

13 Cuando el autor realiza esta crítica, se está refiriendo puntualmente a la filosofía de la religión en la filosofía de la liberación, porque entiende que: "la más desarrollada filosofía de la religión en Hispanoamérica es aquella filosofía fenomenológica que depende de Zubiri" (Solari, 2005: 127). Su caracterización es un tanto infundada, ya que la filosofía fenomenológica de la religión (a la que alude Solari) es la desarrollada por Ignacio Ellacuría -quien sí se asumía dentro de la filosofía de la liberación- y por uno de sus discípulos, Antonio González -quien, si bien pretende superar la filosofía y la teología de la liberación, intenta hacerlo "desde dentro" (Scannone, 2011: 585)-. 
la religión latinoamericana. Algunas de las obras más destacadas que se refieren holísticamente al desarrollo antecedente y contemporáneo del pensamiento latinoamericano poseen una intencionalidad denodadamente complexiva, logrando mostrar de manera suficiente el vasto antecedente histórico de la filosofía latinoamericana, la profundidad de sus planteamientos, la notable diversidad de corrientes y de temáticas y, sobre todo, el alto grado de diferenciación teórica dentro del mismo. ${ }^{14}$ Además, como indica Scannone, se puede advertir la significativa presencia de un conjunto relevante de obras de reciente publicación, especialmente de fines del siglo XX y de comienzos del reciente siglo XXI, dedicadas, en su totalidad o en parte, a la filosofía de la religión latinoamericana. ${ }^{15}$

En definitiva, se podría afirmar que en la actualidad existen tres líneas de investigación predominantes en el campo de la filosofía de la religión en América Latina; las tres están siendo desarrolladas por un conjunto heterogéneo de investigadores jóvenes; pero, a la vez, han sido y son inspiradas por autores de gran envergadura y trayectoria. En primer lugar, hay una corriente que continúa y amplía el camino iniciado por la filosofía «analéctica» de la liberación, una filosofía de la religión propiamente latinoamericana, con Juan Carlos Scannone como el autor más destacado (Scannone, 2005a). En segundo lugar, se advierte la presencia de otra corriente que intenta

14 Entre éstas, vale mencionar: Diccionario de filosofía latinoamericana (Cerutti-Guldberg, 2000); Semillas en el tiempo. El latinoamericanismo filosófico contemporáneo (Jalif de Bertranou, 2001); El pensamiento latinoamericano en el siglo XX (Devés Valdés, 2000; 2003; 2004); Pensamiento Crítico Latinoamericano. Conceptos Fundamentales (Salas Astraín, 2005); Diccionario del pensamiento alternativo (Biagini y Roig, 2009); Historia del pensamiento filosófico latinoamericano. Una búsqueda incesante de la identidad (Beorlegui, 2010); El pensamiento latinoamericano, del Caribe y "latino" [1300-2000]. Historia, corrientes, temas, filósofos (Dussel et. al., 2011); Guía Comares de filosofía Latinoamericana (Beorlegui y Fornet-Betancourt, 2014), entre otras.

15 Entre ellas, se destacan: Religión. Enciclopedia lberoamericana de Filosofía (Gómez Caffarena, 1993); Problemas de filosofía de la religión desde América Latina I. De la experiencia a la reflexión (Durán Casas et. al., 2003); Problemas de filosofía de la religión desde América Latina II. La religión y sus límites (Durán Casas et. al., 2004); “Sobre la filosofía de la religión en América Latina" (Solari, 2005); Religión y nuevo pensamiento. Hacia una filosofía de la religión para nuestro tiempo desde América Latina (Scannone, 2005a); Vislumbres de lo otro. Ensayos sobre Filosofía de la religión (Villoro, 2006); Filosofía y Religión hoy (Beuchot, 2009). 
entablar un diálogo directo con la filosofía analítica, encabezada por la obra de Luis Villoro (Villoro, 2006). En tercer lugar, hay una corriente fenomenológica de la religión, como fenomenología de la excedencia o de la sobreabundancia, liderada magistralmente por Roberto Walton (Walton, 2008; 2010; 2015). En conclusión, Scannone afirma que:

La filosofía de la religión en la América Latina del siglo XX y comienzos del XXI, estuvo y está en continuo diálogo más o menos asuntivo y crítico con las principales corrientes de la filosofía occidental del siglo XX, especialmente con la fenomenología y la hermenéutica, la filosofía analítica del lenguaje, el marxismo y el tomismo. Sin embargo, no deja de tener su idiosincracia, tanto en lo que respecta a planteos originados en nuestro subcontinente -como son los de la FL-, como también en general. Según mi opinión, frecuentemente se sitúa entre tres elementos en tensión que la enriquecen, a saber: 1) la experiencia religiosa -inclusive mística-, 2) el pensamiento especulativo -no pocas veces hondamente metafísico, no ontoteológico-, y 3) la preocupación práctica, tanto estética como ética, y aún política, por el humanismo y la justicia, aunque no siempre todos esos elementos estén presentes, y su acentuación cambie según los autores (Scannone, 2013: 21).

\section{La arqueológica de E. Dussel:Antifetichismo y trascendencia}

En este apartado, se presentan de modo meramente indicativo las notas esenciales de la propuesta arqueológica de E. Dussel, tomando en consideración crítica los análisis que otros reconocidos investigadores han realizado de la misma. En general, la propuesta arqueológica ${ }^{16}$

16 Con la expresión «arqueológica» Dussel se refiere al discurso filosófico que pretende acceder a un ámbito originario en tanto que reflexión sobre el lógos del origen. El origen puede ser comprendido tanto como fundamento ontológico (Grund) o como lo que está «más allá» que el fundamento (lo abisal, lo abismal, Abgrund). Por ello, la arqueológica significa un discurso filosófico-reflexivo que indica "no sólo al fundamento de la totalidad sino también al «desde-donde» la totalidad procede" (Dussel, 2012c: 
que formula Enrique Dussel en su obra filosófica temprana ${ }^{17}$ puede ser entendida como una filosofía de la religión o «mítica». La misma tematiza, centralmente, la cuestión de la «fetichización ontológica» de los sistemas históricos. ${ }^{18}$ Su núcleo discursivo negativo se apoya en una "crítica de la religión”, en tanto ésta puede operar como el “dispositivo sacralizante” más profundo de los sistemas de dominación. Por ello, la mítica auténtica, es decir, la relación re-ligiosa que legitima praxis económico-políticas de liberación debe ser, en

891). La indagación por lo originario ya no se mostrará por la «vía ontológica» (como interioridad o fundamento a priori) sino por la «vía irruptiva exterior» de la alterativometa-física de la liberación (como revelación a posteriori). Para acceder a un análisis detallado de la propuesta arqueológica de Enrique Dussel hay que consultar: "Entender a un Absoluto no contaminado por el sistema desde América Latina. La influencia de Lévinas en la Arqueológica del primer Dussel. Apuntes para una lectura cruzada" (Maddonni, 2016) y "El servicio económico-político como culto antifetichista. Aproximación a la «obra temprana» de Enrique Dussel desde la perspectiva de la «ética arqueológica»" (Zielinski, 2017).

17 La obra filosófica temprana indica el estadio intelectual del autor comprendido en dos etapas temporales: el primer momento consta de las obras escritas entre 1961 y 1968 (construcción de una «antropología filosófica» como «simbólica» cultural latinoamericana) y; el segundo momento, de las obras escritas desde 1969 hasta 1976 (primera formulación sistemática de su filosofía de la liberación). En este trabajo, y por la pertinencia temática correspondiente, tomaré en consideración el segundo momento. La arqueológica es el último tomo de su primera formulación ética sistemática en clave liberadora: Para una ética de la liberación latinoamericana (Dussel, 1973), escrito a finales de 1969; Para una ética de la liberación latinoamericana, t. Il: Eticidad y Moralidad (Dussel, 1973), redactado entre 1971 y 1972; Filosofía ética latinoamericana, t. III: De la erótica a la pedagógica (Dussel, 1977), escrita desde 1972 hasta 1973; Filosofía ética latinoamericana t. IV: La política latinoamericana (Antropológica III) (Dussel, 1979), escrita entre 1973 y 1974 y; Filosofía ética latinoamericana t.V: Arqueológica latinoamericana (Una filosofía de la religión antifetichista) (Dussel, 1980), redactada entre 1974 y 1975. En lo que sigue, citaré la paginación de una edición más reciente del último título: Para una ética de la liberación latinoamericana. Política y Arqueológica (Dussel, 2012C).

18 Para Dussel el proceso de fetichización radica en:"Des-historificar la totalidad social, la formación social concreta. Significa des-dialectizar un proceso que tiene origen, crecimiento, plenitud y fin histórico. El imperio no resiste a reconocerse como un hecho histórico, finito, modificable, que tendrá fin. Posibilidad y contingencia carcomen las pretensiones absolutas del sistema. El fetichismo indica, exactamente, la constitución a-histórica, como pretensión de eternidad (por su origen y término), de la totalidad social vigente. La fetichización consiste en identificar la estructura actual del sistema con la naturaleza (...) con lo que el hombre es por su esencia, con lo que la divinidad ha decidido" (Dussel, 2012C: 978). 
primer lugar y crítico-negativamente, atea del fundamento ontológico de los sistemas vigentes: antifetichista.

El fetichismo es entendido por Dussel como el proceso de sacralización o de divinización del sistema vigente, por el que el «manto de lo divino» consagra lo dado como un Todo irrevocable. En tal fenómeno, la «religión-del-sistema» se posiciona como el "último horizonte de consagración” (Dussel, 2012c: 977). Si se «absolutiza» lo relativo (el sistema histórico, contingente y mutable) se mistifica el orden de cosas dado, generando, en términos representativos (ideológicos), el encubrimiento y la justificación del fundamento del sistema opresor. A su vez, promociona una reproducción pretendidamente infinita de la funcionalidad social, o sea, cristaliza las funciones que cada singular «debe» ocupar «en» la Totalidad del sistema considerándolas como eternas y necesarias. Ante ello, la arqueológica postula un «doble ateísmo»: negativamente, es crítica (atea) del fundamento del sistema y del encubrimiento ideológico que el fenómeno de fetichización legitima al «mistificar» las relaciones de dominación internas. Descree de las estructuras ontológicas fijadas, que sirven de fundamento inconmovible para llevar adelante procesos de dominación y, positivamente, ejerce un «ateísmo por afirmación»a través de una «lógica de la alteridad». Así, el ateísmo adquiere un «sentido positivo», es decir, implica la negación de la injusticia pero por una «vía afirmativa»: la afirmación del Otro «Como otro» (siempre exterior; «resto escatológico de alteridad»). El «Otro» indica, de esta manera, dos modalidades de la exterioridad alterativa: por un lado, el «Otro antropológico» (la «víctima» singular y el pueblo, sujetos de la economía y de la política) y, en distinto nivel pero sólo accesible en la responsabilidad por el primero, el «Otro absolutamente absoluto» (exterioridad infinita nunca del todo representable; tiempo mesiánico de justicia y paz). Desde este marco interpretativo, la «re-ligión» se presenta esencialmente como la "ex-posición re-sponsable por el Otro ante el Otro absolutamente absoluto" (Dussel, 2012c: 924). ${ }^{19}$ Por ello, el «culto» se constituye, en cuanto

19 "La re-ligión no es una dimensión óntica ni ontológica, es decir, no es una «intención» en el sentido fenomenológico, y ni siquiera un «existencial» en el sentido heide- 
tal, en el servicio económico-político justo; modalidad eminente de la justicia en la responsabilidad por el Otro sufriente: "la economía tiene una definición cultual. Dar de comer al hambriento es revolución y liturgia" (Dussel, 2012c: 992).

En particular, y en un pormenorizado estudio de la postulación arqueológica dusseliana, Enzo Solari entiende que ésta debe ser claramente enmarcada dentro de la corriente liberacionista "orientada por el marxismo", dado que el autor constata en su formulación una importante influencia de las categorías de Marx. Sobre todo, se refiere a la utilización de las nociones "religión supraestructural» $\mathrm{y}$ "religión infraestructural $»^{20}$. Estas dos configuraciones históricas de lo religioso indicarían respectivamente las dos posibilidades fundamentales de la funcionalización práctica de la religión: mientras que la religión supraestructural se caracteriza funcionalmente por operar como dispositivo de encubrimiento ideológico de la dominación; la religión infraestructural legitima la práctica re-ligiosa como responsabilidad por el Otro en la praxis político-económica de liberación. El autor destaca que para Dussel la religión se define esencialmente por su concepción y función «infraestructural»; es decir, sostiene que la arqueológica plantea básicamente una contraposición constituyente entre la "religión fetichista» y la «religión liberadora» (Solari, 2005: 129). Por ello, ante el fetichismo religioso, fuente matriz de todo proceso de fetichización histórica (erótico, pedagógico, político o económico), se debe practicar un ateísmo profético radical. Ésta sería una de las principales condiciones de posibilidad, desde la «negatividad» (como negación de la negatividad - «mal

ggeriano. No se trata de la constitución de un cierto objeto como sagrado (como posición de la conciencia) (...) pero tampoco es una apertura al ser como divino. Se trata, en cambio, de una dimensión que está antes que lo ontológico y más allá del ser: es anterior al a priori, es ligazón (como la de la ob-ligación) al Otro, no sólo como interpelante o pro-vocante, sino como necesitante, suplicante, sufriente" (Dussel, 2012C: 924).

20 Solari toma estas categorías de Religión (Dussel, 1977b), compilación de conferencias ofrecidas por E. Dussel en la Universidad de Dubrovnik (Yugoslavia) en el mes de abril de 1977 (dos años después de finalizada la arqueológica -redactada hasta 1975-, aunque publicada recién en 1980). Allí ya es evidente la notoria influencia de Marx, dado que, con posterioridad a su exilio en México (1976), el autor comienza un estudio sistemático de su obra. 
histórico»-que produce el ídolo o «dios-del-sistema»), para plantear una práctica religiosa como culto político-económico auténticamente alterativa. En cuanto a la condición de posibilidad positiva, como ya se ha mencionado, ésta deberá estar basada en la responsabilidad por el Otro "como otro» y, en ello, al modo de la «huella», como culto al Otro absolutamente absoluto (Otro que el cosmos). ${ }^{21}$

21 De todos modos, y en una posición sumamente crítica, Solari sospecha sobre la posible «compatibilidad» entre las diversas fuentes teóricas de Dussel: "Para decirlo en pocas palabras, la de Dussel es una filosofía de la religión levantada sobre tres pilares: Marx, la teología de la liberación y Lévinas (...) La pregunta es si pueden compaginarse adecuadamente estas tres perspectivas. Pienso que no. Se trata de perspectivas esencialmente diversas: una crítica explicativa de la religión (la de Marx), la teología cristiana (en una versión liberadora) y una Fenomenología ética como Filosofía primera (la de Lévinas). La perspectiva fenomenológica, para empezar, debe ser evidente. La perspectiva explicativa, en cambio, no goza de evidencia alguna y debe ser sometida a la contrastación empírica, mientras que la perspectiva teológica supone una participación creyente que no debería ser obligatoria para quien argumente dentro de los márgenes de la filosofía de la religión. Esto, por lo que toca a la combinación de las tres perspectivas" (Solari, 2005: 131). En referencia a esta crítica, considero que el investigador chileno confunde una teoría propia que asume elementos de posturas muy divergentes en una estructura lógica y metodológica coherente con una «sumatoria» de influencias consideradas sin discernimiento (o en su totalidad) y amalgamadas por yuxtaposición una con la otra sin intermediación crítica. De más está decir que asumir elementos de una teoría no implica, en ningún caso, aceptar todo el conjunto de relaciones internas y mundos culturales que esa teoría conlleva. En el caso de la obra temprana de Dussel, si bien hay una notoria influencia de Lévinas y una menor de Marx (ya que Dussel incorporará sistemáticamente la obra de Marx a su filosofía de la liberación con posterioridad), ambos autores son discernidos críticamente y reinterpretados según los fines de la arquitectónica teórica que Dussel construye. Además, considero que esta posición evidencia un cierto desconocimiento de la obra completa de Dussel, ya que, con sólo conocer con precisión el método ana-dia-léctico, se verá con claridad que en esa estructura metodológica hay un momento dialéctico - de negación de la negación, en el que se desarrolla la explicación de los elementos intra-sistémicos en conflicto (Marx)-y, a su vez, hay otro momento de afirmación ana-léctica, meta-física, donde se muestra la pertinencia de una Fenomenología del rostro, en el sentido levinasiano. Estos momentos, si bien se co-implican por "trascendentalidad interior", no se confunden (uno es descriptivo y explicativo (ontológico) y el otro hermenéutico-crítico y normativo (ético-metafísico o trans-ontológico). Por otro lado, Dussel, al igual que Lévinas, no confunde sus obras filosóficas con sus obras teológicas -aunque pueda ir de un registro discursivo al otro con facilidad-. Si bien, la influencia de la teología de la liberación es notoria en Dussel -ies uno de sus fundadores!-, esto no implica que, en términos epistemológicos, confunda las discursividades propias de ambos espacios disciplinares; más bien, se encarga, permanentemente, de delimitarlos. Una vez aclarado este punto, se deja de lado la presunción de que sea necesaria la fe para «aceptar» la filosofía de la religión propuesta por Dussel. 
Por su parte, Pablo Mella comparte en general el análisis que realiza Solari sobre la postulación arqueológica de Dussel, acentuando también en la influencia de Marx: "esta tradición marxista estaría interesada por indagar los límites socio-históricos en los que se desarrolla toda experiencia religiosa" (Mella, 2014: 199). ${ }^{22}$

Por otra parte, Juan Carlos Scannone interpreta notoriamente mejor el sentido general de la propuesta de Dussel. El jesuita pone el acento en el núcleo argumental de la arqueológica: el antifetichismo (Scannone, 2013: 9). ${ }^{23}$ Con ello, precisa puntillosamente la relación entre la ética (responsabilidad por el Otro), el antifetichismo (la anti-idolatría como método) y la re-ligión (culto como servicio económico-político):

La religión (...) (desde el cara-a-cara ético con el otro hombre, a su servicio práxico liberador, frente a Dios) no solo promueve nuevas estructuras e instituciones de justicia y liberación, sino que conserva también un potencial crítico escatológico, aun de esas nuevas estructuras. Pues, en cuanto tales, tienden siempre a totalizarse y, por ende, a fetichizarse y generar víctimas históricas que, porque lo son, permanecen exteriores al sistema (...) Por ello ese pensador emplea el método ana(dia)léctico, ya que la eminencia (propia de la analogía) corresponde a dichas exterioridad y trascendencia éticas y, por su parte, el momento dialéctico, a la negación de la negación, es decir, de la fetichización como negación de la religión auténtica y su culto liberador" (Scannone, 2013: 10).

22 Considero que este tipo de abordaje es un tanto parcial, ya que si fuera únicamente como el autor lo presenta, más que una filosofía de la religión en sentido estricto, Dussel estaría haciendo una sociología crítica de la religión. Estimo que esta incorrecta interpretación tiene lugar porque se sobredimensiona lo propuesto en Religión (Dussel, 1977). Entiendo que esa importante obra debe, no obstante, ser interpretada a la luz de la Arqueológica (Dussel, 1980) para comprender complexivamente el discurso del autor.

23 El antifetichismo y la anti-idolatría dusseliana, además de estar claramente inspirado en las enseñanzas de los profetas de Israel y en la de Marx, mantiene una relación sobreasuntiva con la categoría de «ateísmo» tal como fuera concebida por Emmanuel Lévinas en Totalidad e Infinito (Maddonni, 2016: 255-256). 
Es importante destacar que Scannone, al acentuar en la utilización del método "ana-dia-léctico»" ${ }^{24}$ está indicando el núcleo discursivo de la posición filosófica de Dussel -en lo que respecta a su formulación ética completa (y arqueológica en particular)-. A través de una recomprensión novedosa de la analogía tomista, Dussel construye una concepción original de la trascendencia arqueológica. En general, el «tránsito rítmico» que el método ana-dia-léctico propone se explicaría del siguiente modo: en el nivel práctico de la facticidad («en» lo óntico-«comprensión del ser») se pasa «a través» de él por interpretación existencial hacia un pensar esencial («ontológico-trascendencia derivada» que fundamenta la praxis) hacia un «más allá» antropológico («trans-ontológico»-«trascendencia originaria»; revelación anterior y posterior al fundamento de la praxis: el "Otro"). ${ }^{25}$ La trascendencia ética del Otro ya no es solo la de un

24 A lo largo de toda su obra filosófica temprana, el autor argentino-mexicano expuso sistemáticamente las notas esenciales de este método, sobre todo en las tres obras filosóficas más relevantes de este período: Para una ética de la liberación latinoamericana (Dussel, 2012a: 323-389), publicada en 1973; Método para una filosofía de la liberación. Superación analéctica de la dialéctica hegeliana (Dussel, 2012b: 181-198), publicada en su versión definitiva en 1974 y; Filosofía de la liberación (Dussel, 2006: 233-266), publicada en 1977. En resumidas cuentas, lo que propone allí es: "El método del que queremos hablar, el ana-léctico, va más allá, más arriba, viene desde un nivel más alto (ana-) que el mero método dia-léctico. El método dia-léctico es el camino que la Totalidad realiza en ella misma: desde los entes al fundamento y del fundamento a los entes. De lo que se trata ahora es de un método (o del explícito dominio de las condiciones de posibilidad) que parte desde el Otro como libre, como un más allá del sistema de la Totalidad; que parte entonces desde su palabra, desde la revelación del Otro y que con-fiando en su palabra obra, trabaja, sirve, crea. El método dia-léctico negativo es la expansión de la totalidad desde sí; el pasaje de la potencia al acto de «lo Mismo». El método analéctico es el pasaje al justo crecimiento de la Totalidad desde el Otro y para «servir-le» (al Otro) creativamente. El pasaje de la Totalidad a un nuevo momento de sí misma es siempre dialéctico (...). La verdadera dialéctica tiene un punto de apoyo ana-léctico (es un movimiento ana-dia-léctico); mientras que la falsa, la dominadora e inmoral dia-léctica, es siempre un movimiento conquistador: dia-léctico" (Dussel, 2012a: 355).

25 Como se dijo, este «ritmo lógico» asume, aunque recomprendiéndola, la tríada analógica de Tomás de Aquino: «afirmación», «negación» y «eminencia»: "La ética parte, entonces, de una simbólica, la piensa como dialéctica y la pone en cuestión como analéctica. Se pasa de la ética cotidiana a la ética ontológica, y de ésta, por mediación de la revelación de la ética transexistencial, a la ética meta-física" (Dussel, 2012a: 373). Como ya se señaló, ambos autores, J.C. Scannone y E. Dussel, toman la expresión «analéctica» de B. Lakebrink (Lakebrink, 1955). 
singular irreducible - como para Lévinas- sino la epifanía de un pueblo o de una comunidad histórica concreta: "El rostro del Otro es un aná-logos" (Dussel, 2012a: 356). En términos generales, el método ana-dia-léctico presenta los siguientes momentos (Dussel, 2012a: 356-357): a. el discurso filosófico se dirige dialécticamente desde la cotidianidad óntica hacia el fundamento ontológico; $b$. se demuestran epistemáticamente (científicamente) los entes como posibilidades óntico-existenciales, es decir, la condición fundada de lo óntico en lo ontológico (comprensión del ser estabilizada; fundamento); c. el Otro no se manifiesta meramente como un ente más, sino que se revela como Alguien irreducible a la comprensión desde el horizonte del mundo o de la Totalidad práctica vigente (no es demostrable o deducible a partir del fundamento ontológico); $d$. la revelación del Otro se presenta bajo dos modalidades, ambas configuradas en referencia al tipo de relación que se establece con la Totalidad práctica de sentido, a saber: como «negatividad primera», en tanto es imposible comprenderla «positivamente» desde el «horizonte de sentido» del «mundo» y como «afirmación primera» ya que el horizonte de sentido vigente en la Totalidad puede «contraerse» dando «espacio» para que ella se revele; e. la revelación del Otro como «negatividad primera» destituye "ético-trans-ontológicamente» (lo descubre como «nooriginario») el nivel ontológico y; $f$. el nivel óntico de la Totalidad ontológica antigua queda juzgado y transformado éticamente (praxis analéctica: «servicio» como construcción de una nueva Totalidad analógica). Así, la hospitalidad ante la revelación del Otro como otro implica necesariamente una instancia atea primera: negar la Totalidad, destituir su identidad y su fundamento como lo último (des-totalización anti-fetichista; primer movimiento del «ateísmo arqueológico»). En términos particulares, el método «ana-dia-léctico» funciona como el dispositivo dinamizador que explica el sentido de la trascendencia arqueológica. La "filosofía de la religión" o "Arqueológica de la liberación" gira en su totalidad en torno a la indicación de un ámbito de «trascendencia absoluta» significada de diversas maneras. ${ }^{26} \mathrm{La}$

26 Algunas de ellas son: «Dios alterativo»; «Dios-Otro»; «el Absoluto absolutamente absoluto»; «resto escatológico de exterioriodad»; «Absoluto alterativo»; «utopía esca- 
aludida multiciplicidad de significados de la trascendencia absoluta indica, por plurisemia e indecibilidad, un ámbito incomprensible y siempre excedente. Sin embargo, si se toma como mediación analítica la analogía, la «hermenéutica analógica» o la «analogía hermenéutica» (Scannone, 2005a: 189), se hace posible pensar una «exterioridad absoluta». En la postulación arqueológica de Dussel, la figura del culto al Absolutamente absoluto -afirmación meta-física de una trascendencia absoluta y negación absoluta de todo fetichismo- posee un carácter analógico. Ese carácter es el que posibilita la fundación discursiva de todas las concreciones antropológico-prácticas (erótica, pedagógica, política y económica). Su carácter analógico, en tanto ocupa una posición de «analogado principal», permite predicar sobre un conjunto de experiencias antropológicas concretas, el atributo de «tracendentes»y «ateas». ${ }^{27}$ Dicha predicación refiere analógicamente a la «trascendencia absoluta» y al «antifetichismo absoluto» de modo «semejante» (a través de una «equivocidad ordenada»-ni puramente equívoca ni puramente unívoca-). ${ }^{28}$ Por ello, tanto la trascendencia

tológico-mesiánica»; «supuesto an-arqueológico fundamental»; «resto de excedencia»; "Otro infinito»; "Ausencia»; "Otro que todo sistema»; «hipótesis del Desconocido»; «idea regulativa de justicia y paz»; «justicia perfecta»; «el Utópico»; "Otro que lo vigente»; «Exterioridad del Sagrado», etc.

27 Por ejemplo, una «erótica anti-patriarcal» (atea del falocentrismo) y una «erótica meta-física» (deseo de trascendencia ante el Otro amado); una «pedagógica de-colonial» (atea de la colonialidad del saber) y una «pedagógica meta-física» (el Otro educando como trascendencia desde su positividad cultural); una «anti-política de la dominación» (atea de la totalidad política opresiva) y una «política meta-física» (el «pobre» y el «pueblo» como trascendencia irruptiva). Es por este motivo que tanto J.C. Scannone como L. Maddonni marcan con claridad y rigor la función decisiva que cumple la formulación arqueológica en el proyecto temprano de Dussel: es el último y más importante «punto de apoyo» argumental de su primera arquitectónica ética. Por eso, comparto plenamente la lúcida hipótesis interpretativa que propone Maddonni: "La an-arqueológica (...) es el origen último de la ética (...) Desde la alteridad arqueológica se abren las exterioridades antropológicas (...) El Otro absoluto que descubre la arqueológica, por ser siempre anterior y exterior respecto de los encuentros humanos (pedagógicos, eróticos o políticos), es el garante de que no se totalicen el resto de las relaciones" (Maddonni, 2016: 263). Por ello, afirmo que la arqueológica no solo culmina formalmente toda la arquitectónica ética de cinco volúmenes propuesta por Dussel en su "obra temprana" filosófica, sino que, más radicalmente, la funda constitutivamente. Como queda evidenciado, tal fundación discursiva es sólo posible por «mediación analógica». 
absoluta como el antifetichismo absoluto guardan una relación de «semejanza»-no de sinonimia- con la trascendencia del Otro antropológico en concreciones prácticas y con los ateísmos históricos parciales, respectivamente.

La arqueológica de Enrique Dussel y la filosofía de la religión de la liberación

Una vez presentadas las grandes líneas que propone la arqueológica, se hace necesario, sobre todo por los fines que persigue esta presentación, indicar el plexo categorial referencial que la encuadra en el marco teórico de una filosofía de la religión latinoamericana. El interrogante rector que guía este desarrollo podría formularse del siguiente modo: ¿en qué sentido es posible hablar filosóficamente de la religión a partir de la perspectiva de una filosofía de la religión de la liberación? En primer lugar, partiendo de los presupuestos hermenéuticos de la filosofía «analéctica» de la liberación: $a$. desde la exterioridad, alteridad y trascendencia ético-históricas del Otro, del «pobre», pero reinterpretándolas desde América Latina -no solo en forma personal y ética, sino también y fundamentalmente, desde una perspectiva social, histórica y político-económica-; $b$. usando la mediación de las ciencias sociales correspondientes y; c. releyendo todos los grandes temas de la filosofía a partir del horizonte abierto por la "opción preferencial por los pobres":

Ante el punto de partida del filosofar moderno en el «ego cogito» y su voluntad de poder, dicha filosofía [de la liberación] ${ }^{29}$ lo puso desde el principio en "el oprimido, el marginado, el pobre", en

2005a: 197) que opera como «enlace» entre dos niveles de significación: por un lado, la significación literal que emerge del campo de lo ya conocido (óntico u «horizontal») y, por otro lado, pero sólo accesible a través de la transgresión del primero (por la relación ética), el ámbito relativo a un campo de referencia que no permite una caracterización directa (el de la «trascendencia absoluta» como «antifetichismo absoluto» o el de la «Trascendencia trascendental»-fundación de toda posibilidad de predicación en el campo óntico-).

29 La aclaración es mía. 
su alteridad irreductible -aún dialécticamente irreductible-, en su trascendencia o exterioridad al sistema de opresión, y en su novedad histórica con respecto a ésta. De ahí que no soolo el filósofo como persona sino que también su mismo filosofar deben responder a la interpelación ético-histórica de los pobres, con una opción por ellos, por su liberación humana integral y por la justicia hacia y con ellos (Scannone, 2009a: 68).

Sin embargo, el desafío radica en este momento en la explicitación del modo mediante el cual, a partir del mencionado horizonte hermenéutico general, se realiza la pregunta por la religión y, en ella, por la trascendencia. Desde un abordaje fenomenológico de la religión, ${ }^{30}$ se pretende lograr una descripción de los fenómenos religiosos en su significación e intencionalidad específicas, es decir, en tanto que religiosos. Sin embargo, la filosofía de la religión latinoamericana sentó las bases para dar un paso más allá, a saber: preguntarse por el sentido de la religión no solamente desde un aspecto descriptivo sino, fundamentalmente, normativo (Scannone, 2003: 176). Esto implicó un denodado esfuerzo teórico de la filosofia latinoamericana de la religión en tanto que, reconociendo la situacionalidad histórica inherente a toda reflexión filosófica, recomprendió la respuesta responsable ante los rostros concretos de los otros «desde» un mundo conflictivo e injusto. Requirió, por ejemplo, de Scannone y de Dussel, la formulación de un discurso situado y comprometido que, por vía fenomenológica y hermenéutica, intentara indicar un camino de acceso «normativo», y no meramente fenomenológico,

30 Sobre esta corriente, se puede consultar, como bibliografía introductoria, el artículo "Fenomenología de la religión" (Velasco, 1994 en Fraijó, 1994: 67-87) e Introducción a la fenomenología de la religión (Velasco, 2006). El momento fenomenológico-descriptivo del fenómeno religioso en cuanto tal está precedido por el nivel antropológico-cultural (descripción de hechos y tendencias en el ámbito fáctico de la religión realizada por la mediación de las ciencias del hombre: historia, antropología cultural, psicología religiosa, sociología de la religión, entre otras) (Scannone, 2003: 178). Sobre las «ciencias del hombre» en referencia a la religión, se pueden consultar los siguientes artículos: "Síntesis de historia de las religiones" (Sans, 1994 en Fraijó, 1994: 47-65); "Antropología del hecho religioso" (Duch, 1994 en Fraijó, 1994: 89-115); "Psicología de la religión" (Fierro, 1994 en Fraijó, 1994: 117-132) y; "Sociología del hecho religioso" (Mardones, 1994 en Fraijó, 1994: 133-155). 
al rostro del pobre y a su sabiduría ético-religiosa. De esta manera, la «contextualización» tanto del pensamiento fenomenológico como hermenéutico en América Latina explicitó de manera radical una particular relación con la religión, caracterizada por un replanteamiento crítico de la relación religiosa motivada por la interpelación ético-histórica de los pobres a partir de su alteridad y trascendencia metafísicas. Esto exige hoy, sin más, replantear la cuestión religiosa desde la "pasión injusta de las víctimas":

En esta «edad de la globalización y de la exclusión» (Enrique Dussel) podría ser ideológico o, religiosamente hablando, idolátrico, ejercer la racionalidad filosófica o el lenguaje acerca de Dios sin tener en cuenta la pasión de las víctimas, aun en la comprensión de la racionalidad misma y en la intelección racional de Dios. En las víctimas está en juego lo humano en cuanto tal, y, por ende, la interpretación de qué significan la razón y la auténtica trascendencia racional hacia el misterio santo (Scannone, 2004: 184).

Por tanto, esta «reformulación por contextualización» del lenguaje filosófico sobre la trascendencia, impele, sobre todo, a abandonar todo tipo de praxis totalitaria y todo tipo de pensar totalizante:

El sufrimiento de los inocentes constituye un límite para toda absolutización de la razón misma -teórica o práctica- o de sus productos. El cuestionamiento ético-histórico desde las víctimas no sólo pone en jaque cualquier intento de totalización óntica, teórica, política o religiosa, sino también a la actividad totalizadora misma - a priori- del pensar, hacer y actuar humanos en cuanto tales, pues a la responsabilidad como respuesta-activa-a posteriori, hace preceder la pasión infundada - de las víctimas--, la libre escucha y acogida de su interpelación - a veces muda- y la compasión con su dolor, y aun el carácter infinito de su alteridad y trascendencia éticas, que exceden toda totalización (Scannone, 2004: 187). 
Es decir, el punto de partida para una filosofía de la religión latinoamericana (o en la filosofía de la liberación $)^{31}$ radica en la apertura ético-epistémica a la alteridad de los Otros como otros, pero especialmente en cuanto sufrientes (víctimas de un sistema de opresión de cualquier orden). Es por ello que tanto Scannone como Dussel postulan un filosofar «desde las víctimas de la injusticia». Ambos autores, en su marco teórico-categorial, asumen, por influencia de Franz Rosenzweig y de Emmanuel Lévinas, el «nuevo pensamiento» de raigambre semito-hebrea -como pensamiento judío contemporáneo-, con notas propias muy distintivas. Entre ellas, se podría mencionar la acentuación de las categorías de alteridad (en contraposición con la de «identidad» de la metafísica clásica occidental), de creación (en contraposición con la de «necesidad» predominante en la metafísica occidental clásica), de sensibilidad (en contraposición con la conciencia «cierta de sí», racional y autotransparente, de la modernidad eurocéntrica) y de la novedad histórica imprevisible (en contraposición con la eternidad y con la universalidad abstracta a priori, dominantes en la tradición occidental hegemónica) ${ }^{32}$. Por ello, proponen una «racionalidad nueva», en la que la pasión de las víctimas históricas funciona como principio anti-fetichista y anti-idolátrico ante todo tipo de ideologización de la razón y de la praxis, ${ }^{33}$ situándose contra de todo tipo de «sub-sunción por reducción»: de la alteridad a la identidad, de la novedad al «eterno retorno de lo mismo», de la creación a la necesidad lógica y de la unicidad singular e irrepetible a la universalidad abstracta (Scannone, 2004: 196).

En función de ello, habría que analizar, entonces, cómo se da el replanteamiento de la cuestión religiosa a partir del «nuevo

31 En este caso, equiparo la filosofía latinoamericana a la filosofía de la liberación. Es un uso circunstancial, ya que no juzgo que sean homologables en cuanto tales. Aún más, considero que una identificación de este tipo implica una grave reducción de la filosofía latinoamericana.

32 Estoy siguiendo el sentido general del esquema que propone Scannone (Scannone, 2004: 189), aunque con algunas pequeñas modificaciones de mi autoría.

33 "El hecho de que el nuevo pensamiento surja sobre todo como respuesta a la pasión de las víctimas le exige que, sin dejar de ser metafísico y teórico, sea intrínsecamente ético, práctico e histórico" (Scannone, 2004: 200). 
pensamiento»-como plexo categorial asumido por la filosofía de la religión de la liberación-, sobre todo en referencia a la categoría «trascendencia».

Si se entiende, como aquí hago, a la filosofía de la religión como un preguntarse por el sentido de la religión no solamente desde un aspecto descriptivo (fenomenológico) sino fundamentalmente normativo y a ello se le suma que debe ser «desde América Latina» y «desde la pasión injusta de las víctimas» como lugares hermenéuticos, habría que formular, sin más rodeos, que la trascendencia, como todo aquello que ex-cede la conciencia y el mundo representacional de lo Mismo, es intrínsecamente constitutiva de la ética y de la política. ${ }^{34}$ La relación entre filosofía y trascendencia es, desde siempre, co-implicante, ya que al filosofar le es propia la función metá (lo más allá que-).

Con Dussel, ese «más allá que...» se traduce en un «más allá que el mundo»; es decir, en un ámbito exterior a la «Totalidad ontológica de sentido». En América Latina, el «más allá que...», la función metá del filosofar, indicó la experiencia de la «irrupción de los pobres» como «la» experiencia originaria de lo trascendente. Tal «irrupción de trascendencia» exige, por su pro-vocación, la praxis ética, política y económica de liberación. Sobre la irrupción de los pobres como modelo de trascendencia, explica Scannone: "se trata de una «nueva» experiencia de trascendencia tanto «ética»-pues interpela a la responsabilidad y la solidaridad-como «política», en cuanto el compromiso ético impulsa a luchar por el bien común y la liberación de estructuras injustas, preferencialmente, de las «víctimas» históricas" (Scannone, 2012a: 118). Es decir, esta filosofía de la religión de la liberación tiene que ver sólo parcialmente con un discurso o una praxis «religiosa» (según se usa en el sentido usual del término), ya que, fundamentalmente, está concernida por la experiencia de lo re-ligioso pero en tanto que respuesta responsable - político-económica- ante el sufrimiento del Otro (que revela, por su exterioridad meta-física,

34 "La auténtica trascendencia se juega en las relaciones éticas entre los hombres, el respeto de sus derechos y la transformación de la sociedad en más justa" (Scannone, 2012a: 113). 
señas o signos de trascendencia a lo meramente dado). De esta manera, se presenta como explicitación del marco categorial de la filosofía de la religión de la liberación una recomprensión radical de la trascendencia en tanto que ésta adquiere, sobre todo, un sentido «horizontal» (trascendencia no-ontoteológica en la inmanencia, es decir, un «mesianismo materialista» que entiende la «trascendencia horizontal» - ética y política-como signo de la «trascendencia mesiánica»-lo Otro que lo hasta ahora dado: u-topía escatológica-). ${ }^{35}$

\section{Palabras finales}

Al comienzo de este trabajo, se presentó un breve recorrido histórico del desarrollo de la filosofía de la religión en América Latina, indicando a grandes rasgos los principales temas filosóficos y los autores más significativos de la disciplina practicada en nuestra región durante el siglo XX y comienzos del XXI. Con ello, quedó evidenciado que, especialmente en la «filosofía argentina de la religión», se cuenta con valiosos antecedentes para el tema aquí abordado, no solo de una filosofía de religión en general, sino, más particularmente, una filosofía de la religión «trans-ontológica» que concibe la experiencia humana de lo trascendente a partir de la excedencia y de la trans-objetualidad (es decir, superadora de las posiciones metafísicas

35 La «trascendencia horizontal»-la del otro ser humano pero, sobre todo, la del "pobre, el extranjero, el huérfano y la viuda"- puede ser comprendida, como en Lévinas o en Scannone, como una «huella» en los rostros de los otros de la «trascendencia vertical» de un «Él». Sin embargo, este es solo un camino, monoteísta, de comprensión del tema. Otro abordaje, que considero más cercano al de Dussel, radicaría en pensar la trascendencia horizontal como indicio de una «trascendencia mesiánica»-como lo Otro que lo hasta ahora dado- o de la «utopía escatológica», sin necesidad de atribuirle a ésta última un contenido específico. De hecho, y esta sería una de mis hipótesis principales para abordar la cuestión, considero que la figura del «Otro absolutamente absoluto» en Dussel importa más por su función analógica que por su contenido (aunque pasa por él transgrediéndolo). De todos modos, en todos los casos mencionados, tanto en Dussel como en Scannone y en Lévinas, hay una clara superación de la ontoteo-logía, de manera tal que ese contenido en ningún caso es comprendido como un ente-objeto sometido al imperio de la razón o de la conciencia, más bien se define por su no-definición, in-tematización e irrepresentabilidad (configuración judía heredada por el cristianismo liberacionista de Scannone y Dussel). 
clásicas de carácter onto-teo-lógico). Por tanto, se puede advertir cómo se ha ido elaborando un cierto contexto discursivo específico que fue preparando el camino para la formulación de una filosofía de la religión «en» la filosofía de la liberación (marco en el que Enrique Dussel desarrolla su obra).

En segundo lugar, se han presentado las notas esenciales de la filosofía de la religión dusseliana, la «arqueológica de la liberación», marcando los puntos centrales de su formulación, en especial los siguientes: la moralidad originaria del mal radica en la «totalización totalitaria»; es decir, en el proceso de fetichización de los sistemas históricos. El fetichismo se basa, esencialmente, en la mistificación o en la consagración del orden vigente como un Todo eterno e inmutable. La religión de la dominación puede servir como dispositivo de legitimación último del orden dado; pero a su vez la re-ligión, desde la "filosofía de la mítica liberadora», puede legitimar discursivamente praxis económico-políticas de transformación. Existen, entonces, prácticas cúlticas propias de la «religión supraestructural» (adorar al ídolo del sistema; morir en sacrificio por él) y de la «religión infraestructural» (responsabilidad ética, económico-política, por la vida del pobre, de la viuda, del huérfano y del extranjero). El primer momento, crítico-negativo, de la crítica de la religión («religión infraestructural» o profética) se ejerce como ateísmo del fundamento ontológico de los sistemas vigentes, o sea: como antifetichismo. El segundo momento, crítico-afirmativo, como hospitalidad ante la trascendencia del Santo (el Otro singular y comunitario, como separados; el Otro absolutamente absoluto, más allá que la historia humana comoTotalidad). En definitiva, la re-ligión en la arqueológica se presenta esencialmente como la ex-posición re-sponsable por el Otro ante el Otro absolutamente absoluto y el culto como el servicio económicopolítico justo; modalidad eminente de la justicia en la responsabilidad por el Otro sufriente; la ana-dia-léctica es el dispositivo metodológico que utiliza Dussel para referirse a la «trascendencia absoluta», evitando caer en una excesiva equivocidad o en la pura univocidad; dicho recurso metodológico es una contribución propia y original de la corriente analéctica de la filosofía de la religión latinoamericana (o de la liberación). 
Finalmente, en la tercera sección, se ha intentado enlazar la primera parte del trabajo con la segunda, mostrando analíticamente la pertenencia discursiva de la arqueológica dusseliana a la filosofía de la religión de la liberación. En ello, fueron remarcados algunos elementos centrales, tales como: la exterioridad, la alteridad y la trascendencia ético-históricas del Otro contextualizadas desde América Latina como lugar hermenéutico fundante; una renovada y creativa comprensión de la trascendencia, no solo en la intersubjetividad ética, sino también y fundamentalmente, desde un análisis histórico, social y político-económico; el diálogo permanente con las ciencias sociales; la elección del pobre y del pueblo, de las víctimas históricas singular y comunitariamente comprendidas, como el sujeto de una perspectiva argumental que relocaliza la totalidad de los grandes temas de la filosofía a partir del horizonte que emerge de la "opción preferencial por los pobres"; la pregunta por el sentido de la religión, no solamente desde un aspecto descriptivo sino, sobre todo, normativo y contextualizado; la centralidad de las categorías de alteridad (en contraposición con la de "identidad"), de creación (en contraposición con la de necesidad), de sensibilidad (en contraposición con la conciencia cierta de sí, racional y autotransparente del ego cogito) y de la novedad histórica imprevisible (en contraposición con la eternidad y con la universalidad abstracta a priori); la relación constitutiva entre la cuestión de la trascendencia y los planteamientos éticos, políticos y económicos; un pensamiento esencialmente anti-idolátrico, anti-fetichista y anti-totalitario; una recomprensión radical de la trascendencia en un sentido horizontal (trascendencia horizontal -ética y política- como signo de la trascendencia mesiánica: Utopía escatológica). 


\section{Referencias bibliográficas}

Biagini H. y Roig, A. (Directores). (2009). Diccionario del pensamiento alternativo. Buenos Aires: Biblos.

Beorlegui, C. (1997). "La influencia de E. Lévinas en la filosofía de la liberación de E. Dussel y de J. C. Scannone”. Realidad. Revista de ciencias sociales y humanidades, 57/58, p243-273 / p347-372.

Beorlegui, C. (2010). Historia del pensamiento filosófico latinoamericano. Una búsqueda incesante de la identidad. Bilbao: Deusto Publicaciones.

Beorlegui, C. y Fornet-Betancourt, R. (2014). Guía Comares de filosofía Latinoamericana. Granada: Editorial Comares.

Beuchot, M. (2009). filosofía y Religión hoy. México: Universidad Iberoamericana León.

Cerutti-Guldberg, H. (Dir.). (2000). Diccionario de filosofía latinoamericana. México: UAEM.

Coreth, E., Neidl, W. y Pfligersdorffer, G. (eds.). (1997). Filosofía cristiana en el pensamiento católico de los siglos XIX y XX. Corrientes modernas en el siglo XX, Tomo III. Madrid: Encuentro.

Cruz, G. (2009). La liberación indígena contemporánea en Bolivia. Crítica filosófica a una política-estética racionalizada. Córdoba: EDUCC.

Cullen, C. (1978). Fenomenología de la crisis moral. Sabiduría de la experiencia de los pueblos. San Antonio de Padua: Castañeda.

Cullen, C. (1986). Reflexiones desde América, I. Ser y estar: el problema de la cultura. Rosario: Fundación Ross.

Cullen, C. (1986b). Reflexiones desde América, II. Ciencia y sabiduría: el problema de la filosofía en Latinoamérica. Rosario: Fundación Ross.

Cullen, C. (1987). Reflexiones desde América, III.Yo y nosotros: el problema de la ética y la antropología en Latinoamérica. Rosario: Fundación Ross.

Devés Valdés, E. (2000). El pensamiento latinoamericano en el siglo XX. Del Ariel de Rodó a la CEPAL, Tomo I. Buenos Aires: Biblos-CIDBA.

Devés Valdés, E. (2003). El pensamiento latinoamericano en el siglo XX. Desde la CEPAL al neoliberalismo (1950-1990), Tomo II. Buenos Aires: Biblos-CIDBA.

Devés Valdés, E. (2004). El pensamiento latinoamericano en el siglo XX. Entre la modernización y la identidad, Tomo III. Buenos Aires: Biblos-CIDBA.

Domínguez Miranda, M. (1997). "Filosofía cristiana no escolástica en Latinoamérica". En Coreth, E., Neidl, W. y Pfligersdorffer, G. (eds.). Filosofía cristiana en el pensamiento católico de los siglos XIX y XX. Corrientes modernas en el siglo XX (p624687). Madrid: Encuentro. 
Duch, L. (1994). “Antropología del hecho religioso”. En Fraijó, M. (Dir.). Filosofía de la religión. Estudios y textos (p89-115). Madrid: Trotta.

Durán Casas, V., Scannone, J.C. y Silva, E. (comps.). (2003). Problemas de filosofía de la religión desde América Latina I. De la experiencia a la reflexión. Bogotá: Siglo del Hombre.

Durán Casas, V., Scannone, J.C. y Silva, E. (comps.). (2004). Problemas de filosofía de la religión desde América Latina II. La religión y sus límites. Bogotá: Siglo del Hombre.

Dussel, E. (1973). "El método analéctico y la filosofía latinoamericana”. En AA.VV. Hacia una filosofía de la liberación latinoamericana (p118-137). Buenos Aires: Bonum.

Dussel, E. y Guillot, D. (1975). Liberación latinoamericana y Emmanuel Lévinas. Buenos Aires: Bonum.

Dussel, E. (1977). Filosofía ética latinoamericana, t. III: De la erótica a la pedagógica. México: Edicol.

Dussel, E. (1977b). Religión. México: Edicol.

Dussel, E. (1979). Filosofía ética latinoamericana t. IV: La política latinoamericana (Antropológica III). Bogotá: USTA.

Dussel, E. (2006). Filosofía de la liberación, México: FCE [Primera edición: Dussel, E. (1977). Filosofía de la liberación, México: Edicol].

Dussel, E. (2012a). Para una ética de la liberación latinoamericana, Buenos Aires: Docencia [Primera Edición: Dussel, E. (1973). Para una ética de la liberación latinoamericana, t.I., Buenos Aires: Siglo XXI; Dussel, E. (1973). Para una ética de la liberación latinoamericana, t. II: Eticidad y Moralidad. Buenos Aires: Siglo XXI].

Dussel, E. (2012b). Método para una filosofía de la liberación. Superación analéctica de la dialéctica hegeliana, Buenos Aires: Docencia [Primera Edición: Dussel, E. (1974). Método para una filosofía de la liberación. Superación analéctica de la dialéctica hegeliana. Salamanca: Sígueme].

Dussel, E. (2012c). Para una ética de la liberación latinoamericana. Política y Arqueológica. Buenos Aires: Docencia [Primera edición: Dussel, E. (1980). Filosofía ética latinoamericana t.V: Arqueológica latinoamericana (Una filosofía de la religión antifetichista). Bogotá: USTA].

Ellacuría, I. (1981). “El objeto de la filosofía”. ECA, N 396-397, p 963-980.

Ellacuría, I. (1985). Escritos Políticos I. San Salvador: UCA.

Ellacuría, I. (1990). Filosofía de la realidad histórica. Madrid:Trotta-Fundación Zubiri.

Ellacuría, I. (2000). "La religación, actitud radical del hombre”. En Ellacuría, I. Escritos Teológicos I (p39-105). San Salvador: UCA.

Ellacuría, I. (2001). Escritos Filosóficos III. San Salvador: UCA. 
Ellacuría, I. y Sobrino, J. (2008). Mysterium Liberationis: conceptos fundamentales de la teología de la liberación, Tomo I. San Salvador: UCA.

Esperón, J.P., Scannone, J.C., Walton, R. (eds). (2015). Trascendencia y sobreabundancia. Fenomenología de la religión y filosofía primera. Buenos Aires: Biblos.

Fatone, V. (1955). El hombre y Dios. Buenos Aires: Ed. Columba.

Fierro, A. (1994). "Psicología de la religión”. En Fraijó, M. (Dir.). Filosofía de la religión. Estudios y textos (p117-132). Madrid: Trotta.

Fornet-Betancourt, R. (1988). Philosophie und Theologie der Befreiung. Frankfurt: Materialis Verlag.

Fraijó, M. (Dir.) (1994). Filosofía de la religión. Estudios y textos. Madrid: Trotta.

García Bazán, F. (1980). “Vicente Fatone y la filosofía de la religión en la Argentina”. Cuyo,Vol. 13, pp. 25-40.

García Bazán, F. (1999). Aspectos inusuales de lo sagrado. Madrid: Trotta.

García Clarck, R. (2000). “Filosofía de la liberación”. En Cerutti-Guldberg, H. Diccionario de Filosofía Latinoamericana (p169-170). Toluca: UAEM.

Gomez Caffarena, J. y Velazco, J.M. (1973). Filosofía de la religión. Madrid: Revista de Occidente.

Jalif de Bertranou, C.A. (2001). Semillas en el tiempo. El latinoamericanismo filosófico contemporáneo. Mendoza: EDIUNC.

Kusch, R. (1962). América profunda. Buenos Aires: Hachette.

Kusch, R. (1973). "El «estar siendo» como estructura existencial y como decisión cultural americana". En Actas II del II Congreso Nacional de Filosofía (Córdoba 1971). Córdoba: Sudamericana.

Kusch, R. (1975). La negación del pensamiento popular. Buenos Aires: Cimarrón.

Kusch, R. (1977). El pensamiento indígena y popular en América. Buenos Aires: Hachette.

Lakebrink, B. (1955). Hegels dialektische Ontologie und die thomistische Analektik. Köln: Bachem.

Lévinas, E. (1968). Totalité et infini. Essai sur I'exteriorité. La Haya: Nijhoff.

Lévinas, E. (1974). Autrement qu'être ou au-dela de I'essence. La Haya: Nijhoff.

Maddonni, L. (2016). "Entender a un Absoluto no contaminado por el sistema desde América Latina. La influencia de Levinas en la arqueológica del primer Dussel. Apuntes para una lectura cruzada. En Blanco Araujo, A. (Comp.). Pensar en torno al Númen. Religación desde la América profunda II (p245-264). Buenos Aires: Ediciones del signo.

Mardones, J.M. (1994). “Sociología del hecho religioso”. En Fraijó, M. (Dir.). Filosofía de la religión. Estudios y textos (p133-155). Madrid: Trotta. 
Marquínez Argote, G. (1981). Filosofía de la religión. Bogotá: USTA.

Massuh, V. (1965). El rito y lo sagrado. Buenos Aires: Columba.

Massuh, V. (1975). Nihilismo y experiencia extrema. Buenos Aires: Sudamericana.

Mella, (2014). "La filosofía cristiana y la filosofía de la religión en Latinoamérica". En Beorlegui, C. y Fornet-Betancourt, R. Guía Comares de filosofía latinoamericana (p191-210). Granada: Editorial Comares.

Quiles, I. (1958). Más allá del existencialismo. Filosofía in-sistencial. Barcelona: L. Miracle.

Quiles, I. (1980). La persona humana. Buenos Aires: Depalma.

Rodó, J.E. (2005). Ariel. Buenos Aires: El Andariego.

Rougès, A. (1943). La jerarquía del ser y la eternidad. Tucumán: UNT.

Samour, H. (2014). "Las filosofías de la liberación”. En Beorlegui, C. y Fornet-Betancourt, R. Guía Comares de filosofía latinoamericana (p213-245). Granada: Editorial Comares.

Salas Astrain, R. (Coord.). (2005). Pensamiento Crítico Latinoamericano. Conceptos Fundamentales, 3 vols., Santiago de Chile: Universidad Católica Silva Henríquez.

Sans, I.M. (1994). “Síntesis de historia de las religiones”. En Fraijó, M. (Dir.). (1994). Filosofía de la religión. Estudios y textos (p47-65). Madrid: Trotta.

Scannone, J.C. (1976). Teología de la liberación y praxis popular. Aportes críticos para una teología de la liberación. Salamanca: Sígueme.

Scannone, J.C. (1989). “Fenomenología y religión”, Estudios Eclesiásticos, 64, p 133-139.

Scannone, J.C. (1990). Nuevo punto de partida en la filosofía latinoamericana. Buenos Aires: Guadalupe.

Scannone, J.C. (1993). "Liberación. Un aporte original del cristianismo latinoamericano”. En Gómez Caffarena, J. (ed.). Religión. Enciclopedia Iberoamericana de Filosofía (p93-105), Vol. 3. Madrid: Trotta.

Scannone, J.C. (2003). “De la fenomenología de la religión en América Latina a una Filosofía de la religión”. En Durán Casas, V., Scannone, J.C. y Silva, E. (comps.). Problemas de filosofía de la religión desde América Latina I. De la experiencia a la reflexión (p175-208). Bogotá: Siglo del Hombre.

Scannone, J.C. (2004). "Dios desde las víctimas. Contribución para una 'nuevo pensamiento’”. En Durán Casas, V., Scannone, J.C. y Silva, E. (comps.). Problemas de filosofía de la religión desde América Latina II. La religión y sus límites (p183-210). Bogotá: Siglo del Hombre.

Scannone, J.C. (2005a). Religión y nuevo pensamiento. Hacia una filosofía de la religión para nuestro tiempo desde América Latina. Barcelona-México D.F: AnthroposUAM (Iztapalapa). 
Scannone, J.C. (2005b). “Los fenómenos saturados según Jean-Luc Marion y la fenomenología de la religión”, Stromata, 61, p1-15.

Scannone, J.C. (2005c). "Fenomenología y hermenéutica en la 'Fenomenología de la donación’ de Jean-Luc Marion”, Stromata, 61, p179-193.

Scannone, J.C (2005d). "Filosofía/Teología de la liberación”. En Salas Astraín, R. (Coord.). Pensamiento Crítico Latinoamericano. Conceptos Fundamentales (p429441), Vol. III. Santiago de Chile: Universidad Católica Silva Henríquez.

Scannone, J.C. (2009a). "La filosofía de la liberación: historia, características, vigencia actual”. Teología y Vida, Vol. L. Buenos Aires: U.C.A., p59-73.

Scannone, J.C (2009b), "Erbe und Auftrag der Phänomenologie Bernhard Weltes für die lateinamerikanische Philosophie. Ein Dialog mit dem phänomenologischen Ansatz Jean-Luc Marions“. En Eckholt, M. (ed.). „Clash of civilizations“ oder Begegnung der Kulturen aus dem Geist des Evangeliums. Bernhard Weltes Impulse für den interkulturellen Dialog mit Lateinamerika (p97-112), Berlin: Intercambio-Schriftenreihe. Schriften des Stipendienwerkes Lateinamerika-Deutschland.

Scannone, J.C. (2010a). "Reflexiones filosóficas sobre la situación actual de la religión en América Latina”. En Bidon-Chanal, L. y Puggari, I. (comp.). Religión y después. Sobre esperas, abandonos y regresos (p25-49). Buenos Aires: Baudino.

Scannone, J.C. (2010b). “Aportaciones de la fenomenología de la religión a la teología fundamental”, Stromata, 46, p135-149.

Scannone, J.C. (2011). “La filosofía de la religión”. En Dussel, E., Mendieta, E., Bohórquez, C., El pensamiento latinoamericano, del Caribe y "latino" [1300-2000]. Historia, corrientes, temas, filósofos (p581-594). Buenos Aires-México: Siglo XXI.

Scannone, J.C. (2012a). "La trascendencia como intrínsecamente constitutiva de ética y política”, Open Insight, 3, p113-127.

Scannone, J.C. (2012b). “Nuevo pensamiento, analogía y anadialéctica”. En Stromata, $68, \mathrm{p} 33-56$.

Scannone, J.C. (2013). "Filosofía de la religión en América Latina (siglo XX)". Manuscrito inédito.

Solari, E. (2005) “Sobre la filosofía de la religión en América Latina”. Realidad. Revista de Ciencias Sociales y Humanidades, $N^{\circ} 103$, p127-169.

Solís Bello Ortiz, N.L., Zúñiga, J., Galindo, M.S., Gozález Melchor, M.A. (2011). "La filosofía de la liberación”. En Dussel, E., Mendieta, E., Bohórquez, C., E1 pensamiento latinoamericano, del Caribe y "latino" [1300-2000]. Historia, corrientes, temas, filósofos (p399-417). Buenos Aires-México: Siglo XXI.

Vassallo, A. (1950). Elogio de la vigilia. Buenos Aires: Emecé.

Vasconcelos, J. (1952). Todología. Filosofía de la coordinación. México: Botas.

Vaz, H. C. (1968). Ontologia e história, São Paulo: Duas Cidades. 
Vaz, H. C. (1986). Escritos de filosofía. Problemas de fronteira. São Paulo: Loyola.

Vaz, H. C. (1988). Escritos de filosofía II: Ética y cultura. São Paulo: Loyola.

Vaz, H. C. (1991). Antropología filosófica I. São Paulo: Loyola.

Vaz, H. C. (1992). Antropología filosófica II. São Paulo: Loyola.

Vaz, H. C. (2000). Experiencia mística e filosofia na tradicào occidental. São Paulo: Loyola.

Velasco, J.M. (1994). “Fenomenología de la religión”. En Fraijó, M. (Dir.). (1994). Filosofía de la religión. Estudios y textos (p67-87). Madrid: Trotta.

Velasco, J.M. (2006). Introducción a la fenomenología de la religión. Madrid:Trotta.

Vélez Correa, J. (1991). Al encuentro de Dios. Filosofía de la religión. Bogotá: CELAM.

Villoro, L. (1982). Creer, saber, conocer. México: Siglo XXI.

Villoro, L. (2006). Vislumbres de lo otro. Ensayos sobre Filosofía de la religión. México: Verdehalago.

Virasoro, M.A. (1965). La intuición metafísica. Buenos Aires: Lohlé.

Walton, R. (2008). "Reducción fenomenológica y figuras de la excedencia". Tópicos. Revista de Filosofía de Santa Fe, No 18, p169-187.

Walton, R. (2010). "El giro teológico como retorno a los orígenes: la fenomenología de la excendencia”. Pensamiento y cultura. Universidad de la Sabana, 13, p127-140.

Zielinski, J.M. (2017). "El servicio económico-político como culto antifetichista. Aproximación a la 'obra temprana' de Enrique Dussel desde la perspectiva de la “ética arqueológica”. En Franciscanum, N¹67, Vol. LIX, p77-118. 